\title{
Upfront
}

\section{Accra Political Statement on Inequalities in the Context of Structural Transformation Accra, Ghana: 28-30 April 2014*}

We - the representatives of African governments, Pan-African regional institutions, civil society, private sector, human rights and development practitioners, academia, and development partners - having convened in Accra at the Pan African Conference on 'Inequalities in the Context of Structural Transformation' hosted by the Government of Ghana and organized in partnership with several national, regional and international institutions - do hereby declare:

Inequality is a critical and defining challenge for Africa. The recent experience in most African countries reveals that while growth has been remarkable over the last decade it has occurred alongside limited decent job opportunities and stark inequalities in income, wealth and access to social services. In many countries, the current growth pattern has actually increased the dependence on the export of primary commodities and minerals and often led to premature deindustrialization and stagnation of agricultural productivity. The growth in African demand has therefore often translated in increased import of food and manufactured products and the virtual export of African jobs and human capabilities. Furthermore, trends of decreasing African ownership of its assets as well as shirking retention of the benefits of its growth are of great concern and speak to the heart of the global inequality problem.

In this context, we appreciated the opportunity to build an increasingly common understanding of the complexity of inequalities as they relate to multiple domains (economic, social and political) and cut across many different divides (gender, social groups, generations, spatial distribution). However different and segmented inequalities may be, they manifest, on the one hand, the underlying structures of horizontal power relations across gender, social groups and communities, and, on the other hand and even more so, they reflect the vertical structures of inequalities between capital and labor both domestically and globally. The different dimensions of inequalities therefore share common roots.

We concurred that most forms of inequalities are closely interconnected and can only be fully understood in the interplay of the spheres where they manifest themselves. We debated our conceptual and political differences and appreciated our diversities in experiences and perspectives. Nevertheless, we strongly felt that - however different our positions, spheres of work and domains of action may be - we all share a common aspiration for the full realization of the social, economic and political rights of the African people to enjoy meaningful lives within inclusive, equitable and sustainable societies and economies.

We therefore welcome the agenda for structural transformation that Africa is beginning to shape and actively engage both regionally and nationally. The promotion of increased value addition, economic diversification, inclusive and sustainable industrial 
development, and people-centered agricultural transformation are all necessary condition to further augment the progress the continent has recently experienced and redress the global division of labor that has traditionally relegated Africa to being the mere producer of primary commodities and minerals. While necessary, this is not sufficient to respond the conditions of inequity and deprivation that still prevail across the continent unless the explicit intent to rebalance the widening gaps in inclusion and equity is placed at the very core of the continental development agenda. We therefore urge that the further elaboration of the structural transformation agenda would embrace deliberate policies to tackle economic, social and political inequalities.

In this respect, we have discussed the increasing focus on inclusive growth and felt the need to qualify this concept for it to respond to the fundamental thrust that brought us here together in Accra. We recognize and fully support the quest for greater job-intensity of growth. However, economic inclusion cannot be decoupled from the quest for dignity and equity and employment cannot alone resolve the extent of the current inequality divides. Deliberate policies to promote income and asset equity, facilitate human development and social inclusion, and promote the sharing of political power and access to the benefits of national resources are required to tackle inequalities and promote the real transformation of our societies and economies.

We all urge a legitimate and capable developmental State to drive this policy renewal to tackle inequalities and promote such people-centered transformation of our societies and economies. In this context, new fair and effective taxation regimes, measures to curb illicit capital flows and combat corruption can generate the resources for the necessary public investments and accountable development financing strategies. At the same time, the need for evidence-based policies require significant investment in independent and publicly accountable statistical capacities to ensure that real social and economic needs and dynamics are located and addressed and progress (or lack of it) can be adequately tracked over time.

However, the agenda for inclusion and equity requires a much broader agency that the State alone. It involves a fundamental change in power relations and the democratic negotiation of a new social contract between citizens and accountable and developmental democratic institutions. We therefore welcome the diversity of actors in the conference as a solid base on which to build the necessary harmonious and participatory interaction for the full legitimacy of decision-making within our societies.

We are deeply committed to continue to deepen our engagement to tackle inequalities and promote the transformation of our societies and economies, and to advance our common struggle for fair, just and egalitarian societies in which the needs of the most vulnerable are given genuine priority in the process, action and outcomes of the new development agenda.

Accra, 30 April 2014.

\footnotetext{
*This is the political declaration endorsed by the Africa-wide Conference on 'Inequalities in the context of Structural Transformation', convened by the Government of Ghana in collaboration with many African and international partner organizations. The conference was held in Accra, Ghana, on 28th-30th April 2014. For more information, please visit http://africainequalities.org/conference/.
} 